\title{
Unrepaired rotator cuff tears following acromioplasty
}

\author{
Chivers $\mathrm{D}^{1} \stackrel{\oplus}{ }$, Lambrechts $\mathrm{A}^{2}$, Vrettos $\mathrm{B}^{3}$, Dachs $\mathrm{R}^{4} \oplus$, Roche $\mathrm{S}^{5}$
}

1 MBChB, MMed(UCT), FCS(SA)Orth; Orthopaedic consultant, Port Shepstone Hospital; Department Orthopaedic Surgery, University of Cape Town, Cape Town, South Africa

2 MBChB, MMed(Orth); Orthopaedic surgeon, Constantiaberg Hospital, Cape Town; University of Cape Town, Cape Town, South Africa

3 MBChB, FCS(SA)Orth, FRCS; Honorary professor, Shoulder and Elbow unit, Groote Schuur Hospital, University of Cape Town, Cape Town, South Africa

4 MBChB, FCS(SA) Orth; Consultant, Shoulder and Elbow unit, Groote Schuur Hospital, University of Cape Town, Cape Town, South Africa

5 MBChB, FCS(SA) Orth; Professor, Head of Shoulder and Elbow unit, Groote Schuur Hospital, University of Cape Town, Cape Town, South Africa

Corresponding author: Dr D Chivers, PO Box 306, Shelly Beach 4265, KwaZulu-Natal; email: davechivers78@gmail.com; cell: 0829037691

\section{Abstract}

Background: The natural history of rotator cuff tears suggests that not all tears progress and small isolated rotator cuff tears might heal. To date there have been no long-term studies assessing the MRI changes of unrepaired full thickness supraspinatus tears after acromioplasty.

Methods: A database of patients from a single surgeon that have had acromioplasty without rotator cuff repair in the last five to 15 years was reviewed. The number of shoulders examined in this study was 17. Patients all completed an Oxford score, Constant score and had an MRI to assess fatty infiltration and atrophy.

Results: Mean follow-up time 7.2 years (range, 5-13 years). The patients were divided into three groups depending on the size of the tear at time of surgery: $C 1$ tears $(<1 \mathrm{~cm}) n=5$, C2 tears $(1-1.9 \mathrm{~cm}) n=8, C 3$ tears $(2-3 \mathrm{~cm}) n=4$. In the C2 group, MRI evaluation showed there were two patients that had tears that had regressed in size (Cl 1.4-36, 4). In the $\mathrm{C} 3$ group, MRI evaluation revealed that all $(100 \%)$ of the rotator cuff tears had significant fatty infiltration and atrophy. There was no statistical difference between groups when assessing Oxford scores $(p=0.75)$ and Constant scores $(p=0.69)$. There was significant association between increase in tear size and fatty infiltration $(p=0.028)$. A possible association was noted between increase in tear size and atrophy $(p=0.054)$.

Conclusion: Patients had good long-term clinical outcomes irrespective of tear size. It showed that not all tears progressed to significant fatty change and atrophy.

Level of evidence: Level 3

Key words: unrepaired, full thickness supraspinatus tear, acromioplasty

Citation: Chivers D, Lambrechts A, Vrettos B, Dachs R, Roche S. Unrepaired rotator cuff tears following acromioplasty. SA Orthop J 2019;18(3):47-52. http://dx.doi.org/10.17159/2309-8309/2019/v18n3a5

Editor: Prof LC Marais, University of KwaZulu-Natal, Durban, South Africa

Received: September $2018 \quad$ Accepted: May $2019 \quad$ Published: August 2019

Copyright: () 2019 Chivers D, et al. This is an open-access article distributed under the terms of the Creative Commons Attribution Licence, which permits unrestricted use, distribution and reproduction in any medium, provided the original author and source are credited.

Funding: No financial remuneration was received by any of the authors for this study.

Conflict of interest: The authors declare that there is no conflict of interest regarding the publication of this paper. 


\section{Introduction}

Impingement syndrome and its association with rotator cuff tears is well documented. The clinical outcome after acromioplasty has been well researched and the literature reports good long-term results. Debate, however, continues regarding the optimal and most cost-effective treatment of the older patient group with an associated rotator cuff tear, with studies reporting good functional outcomes without rotator cuff repair. ${ }^{1}$

Recent studies have assessed the structural changes of unrepaired rotator cuff tears; however, there has been little research into the long-term clinical outcomes and MRI changes in isolated full thickness tears of supraspinatus after acromioplasty.

The aim of this study was to evaluate the long-term clinical and structural outcomes of a cohort of patients with isolated full thickness tears of supraspinatus who underwent an acromioplasty without rotator cuff repair.

\section{Methods and material}

The cohort consisted of patients from a single surgeon database who had been operated on for symptomatic impingement syndrome without repair of a full thickness supraspinatus tear diagnosed at arthroscopy. Tears were categorised as $\mathrm{C} 1$ (less than $1 \mathrm{~cm}$ ), C2 (between 1 and $1.9 \mathrm{~cm}$ ), and $\mathrm{C} 3$ (between 2 and $3 \mathrm{~cm}$ ) according to the Snyder classification. ${ }^{2}$

All $\mathrm{C} 1$ and $\mathrm{C} 2$ rotator cuff tears at arthroscopy were noted to be within the rotator cable as postulated by Burkhart et al. ${ }^{3}$

All patients had failed conservative treatment, and on examination had full active abduction, forward elevation and external rotation, minimal weakness of supraspinatus and full strength of infraspinatus and subscapularis.

Exclusion criteria were follow-up of less than five years, rheumatoid arthritis, diabetes, long-term corticosteroid use, and previous surgery to the shoulder.

Of the 64 patients contacted telephonically, 16 agreed to participate. The other 48 patients were either not contactable, were too ill, had relocated or had passed away.

We had 16 patients that met these criteria; of these 16 patients, there was one patient that had bilateral pathology, so the number of shoulders investigated was $17(n=17)$.

\section{Imaging}

Patients did not receive an MRI on presentation to the primary surgeon as it was not clinically indicated at the time, but were assessed clinically and had X-ray confirmation of type 3 acromial morphology as described by Bigliani et al. ${ }^{2}$

On follow-up, all study participants had an MRI of both shoulders. The MRI images were assessed by an experienced musculoskeletal radiologist and a fellowship-trained shoulder surgeon who had no information regarding the patients' clinical outcome.

Continuity or rupture was assessed on T2-weighted coronal imaging sequence. A tear was diagnosed if there was no continuity in the muscle fibres of the rotator cuff.

The quality and quantity of the rotator cuff was assessed on parasagital T1-weighted turbospin echo images taken parallel to the glenohumeral joint.

Table I: Comparison of tear size and age at surgery/follow-up

\begin{tabular}{|l|c|c|c|}
\hline & C1 tears & C2 tears & C3 tears \\
\hline Age at surgery & 60.4 years & 65 years & 69 years \\
(range years) & $(49-75)$ & $(58-71)$ & $(59-73)$ \\
\hline Age at follow-up & 67.4 years & 76.7years & 76.2 years \\
(range years) & $(60-82)$ & $(69-81)$ & $(72-83)$ \\
\hline
\end{tabular}

Fatty infiltration was assessed as described by Goutallier et al., ${ }^{5}$ modified by Fuchs et al. ${ }^{6}$ for MRI.

Supraspinatus atrophy was determined using the tangent sign as described by Zanetti et al. ${ }^{7}$

\section{Clinical assessment}

Clinical assessment was done according to a standardised technique using a handheld goniometer and dynamometer.

The Constant score ${ }^{8}$ was recorded where a maximum of 100 points could be obtained. Shoulder range of movement was measured using a handheld goniometer as described by Constant and Murley. ${ }^{8}$ Abduction strength was measured using a handheld dynamometer applied to the wrist. The arm was abducted in the scapular plane, elbow extended, and forearm pronated. Three readings were taken and the average of the three readings was recorded.

An Oxford score ${ }^{9}$ was completed by all patients examined, where a maximum score of 48 could be obtained.

\section{Statistical methods}

The data was analysed using Stata 13.0 (Statacorp LP, 4905 Lakeway Drive, College Station, TX77845, USA). Categorical data between the groups was analysed using the chi-squared test or Fisher's exact test as appropriate. Normality of continuous data was assessed using the Shapiro Wilk test. Normally distributed data was summarised using means and standard deviations, and compared using the Student's t-test. Skewed data was summarised using medians and ranges, and groups compared using the MannWhitney test. Statistical significance was set at $p<0.05$ and all tests were two-sided.

\section{Results}

There were 17 shoulders in 16 patients (nine females). Mean followup was 7.2 years (range, $5-13$ years). The mean age at surgery was 65.8 years (range, $50-82$ years) and the mean age at most recent follow-up was 73 years (range, 60-89 years).

The patients were divided into three groups depending on the size of the tear at time of arthroscopy. In this study, we had five $\mathrm{C} 1$ tears, eight $\mathrm{C} 2$ tears and four C3 tears (Table I).

\section{C1 tears $(n=5)$}

The average age at surgery was 60.4 years (range, 49-75 years). The average age of patients with $\mathrm{C} 1$ tears at most recent follow-up was 67.4 years (range, $60-82$ years).

The median Constant score was 86 (range 83-96) and median Oxford score was 47 (range 46-48).

Only one patient in the $\mathrm{C} 1$ tear group had significant fatty infiltration (grade IV) and a positive tangent sign indicating significant muscle atrophy.

\section{C2 tears $(n=8)$}

The average age at surgery was 65.3 years (range, 58-81 years). The average age of patients with C2 tears at most recent follow-up was 76.7 years (range, 69-81 years). The mean Constant score was 72.3 (range 62-98) and mean Oxford score was 45 (range 42-48).

Only one patient in this group had significant fatty infiltration (grade IV).

On MRI two tears in the group had regressed in size and were reported as partial thickness tears. 
Table II: Table showing the clinical parameters for the three categories of tear (based on tear size at surgery) ( $\mathrm{n}=17$ )

\begin{tabular}{|c|c|c|c|c|}
\hline & C1 tears & C2 tears & C3 tears & $p$-value \\
\hline Mean abduction in $\mathrm{kg}$ (SD) & $11.1(7.5)$ & $11.9(7.1)$ & $6.4(3.3)$ & ${ }^{*} p=0.4$ \\
\hline $\begin{array}{l}\text { Mean forward flexion } \\
\text { Degrees (SD) }\end{array}$ & $168.2(7.5)$ & $170(7.8)$ & $157.2(7.2)$ & ${ }^{*} p=0.04$ \\
\hline $\begin{array}{l}\text { Mean lateral elevation } \\
\text { Degrees (SD) }\end{array}$ & $171(4.3)$ & $170.8(5.2)$ & $162.8(5.9)$ & ${ }^{*} p=0.04$ \\
\hline $\begin{array}{l}\text { Median external rotation average (range) } \\
\star * * \\
\text { see key }\end{array}$ & $4(2-5)$ & $5(5-5)$ & $4.5(3-5)$ & ${ }^{* *} p=0.7$ \\
\hline $\begin{array}{l}\text { Median internal rotation } \\
\text { Average (range) } \\
\text { * see key }\end{array}$ & $5(5-6)$ & $5(5-6)$ & $5(5-6)$ & ${ }^{* *} p=0.8$ \\
\hline
\end{tabular}

*Means were compared between the three categories using ANOVA

${ }^{* *}$ Medians were compared between the three categories using the Mann-Whitney $\mathrm{U}$ test

*** External rotation: 1) hand behind head, elbow forward; 2) hand behind head, elbow back; 3) hand to top of head, elbow forward; 4) hand to top of head, elbow back;

5) full elevation

*** Internal rotation: 1) lateral thigh; 2) buttock; 3) lumbosacral junction; 4) waist; 5) T12 vertebra; 6) interscapular T7

Table III: Comparison of median Oxford and median Constant scores by tear size $(n=17)$

\begin{tabular}{|l|c|c|c|}
\hline & C1 & C2 & C3 \\
\hline Median Oxford score (range) & $47(25-48)$ & $45(37-48)$ & $45(42-48)$ \\
\hline Median Constant score (range) & $86(52-96)$ & $72.3(78-98)$ & $72.3(65-86)$
\end{tabular}

Medians were compared between the three groups using Kruskall-Wallis chi-squared test.

Table IV: Comparison of tear size and proportion of muscle with fatty infiltration at follow-up, $\mathrm{n}=17$

\begin{tabular}{|l|l|l|l|l|l|} 
& $\begin{array}{c}\text { Stage 0 } \\
(\%)\end{array}$ & $\begin{array}{c}\text { Stage 1 } \\
(\%)\end{array}$ & $\begin{array}{c}\text { Stage 2 } \\
(\%)\end{array}$ & $\begin{array}{c}\text { Stage 3 } \\
(\%)\end{array}$ & $\begin{array}{c}\text { Stage 4 } \\
(\%)\end{array}$ \\
\hline C1 tears & 40.0 & 20.0 & 20.0 & 20.0 & 0.0 \\
\hline C2 tears & 0.0 & 62.0 & 25.0 & 0.0 & 12.5 \\
\hline C3 tears & 0.0 & 0.0 & 0.0 & 0.0 & 100.0 \\
\hline
\end{tabular}

(Fisher's exact test, $\mathrm{p}=0.028$ )
Table V: Comparison of tear size and proportion atrophy

\begin{tabular}{|l|c|c|} 
& $\begin{array}{c}\text { Tangent sign negative } \\
(\%)\end{array}$ & $\begin{array}{c}\text { Tangent sign positive } \\
(\%)\end{array}$ \\
\hline C1 tear & 80.0 & 20.0 \\
\hline C2 tear & 75.0 & 25.0 \\
\hline C3 tear & 0.0 & 100.0 \\
\hline
\end{tabular}

(Fisher's exact test, $\mathrm{p}=0.032$ )

Table VI: Comparison of fatty infiltration and abduction strength

\begin{tabular}{|c|c|c|c|c|c|}
\hline $\begin{array}{l}\text { Fatty infiltration stage } \\
\left(\text { Goutallier }{ }^{5}\right)\end{array}$ & $\begin{array}{l}\text { Stage } 0 \\
(n=2)\end{array}$ & $\begin{array}{l}\text { Stage } 1 \\
(n=6)\end{array}$ & $\begin{array}{l}\text { Stage } 2 \\
(n=4)\end{array}$ & $\begin{array}{c}\text { Stage } 3 \\
(n=1)\end{array}$ & $\begin{array}{l}\text { Stage } 4 \\
(n=4)\end{array}$ \\
\hline $\begin{array}{l}\text { Mean abduction } \\
\text { strength } \mathrm{kg} \\
\text { (range kg) }\end{array}$ & $\begin{array}{c}9.4 \mathrm{~kg} \\
(4.8-14.0)\end{array}$ & $\begin{array}{c}16.0 \mathrm{~kg} \\
(6.6-22)\end{array}$ & $\begin{array}{c}10.4 \mathrm{~kg} \\
(5.3-15.3)\end{array}$ & $3.5 \mathrm{~kg}$ & $\begin{array}{c}4.2 \mathrm{~kg} \\
(1.4-8.4)\end{array}$ \\
\hline
\end{tabular}

Spearman's rho, $p=0.009$

\section{C3 tears $(n=4)$}

The average age at surgery was 69 years (range, 59-73 years) The average age of patients with $\mathrm{C} 3$ tears at most recent follow-up was 76.2 years (range, 72-83 years). The mean Constant score was 72.3 (range 65-98). The mean Oxford score was 45 (range, 42-48).

On MRI all four patients had stage 4 fatty infiltration and a positive tangent sign.

\section{Comparison of clinical parameters}

There was no significant difference between the three groups when comparing abduction strength: Oneway ANOVA $p=0.31$ ); internal rotation (Kruskall-Wallis chi-squared $p=0.8$ ); and external rotation Kruskall-Wallis chi-squared $p=0.7$ ). There was, however, a statistical difference in range of motion when comparing forward flexion (Oneway ANOVA $\mathrm{p}=0.04$ ); and lateral elevation (Oneway ANOVA $p=0.04$ ) between the three categories of tears (Table II).

There was no significant difference in Oxford (Kruskall-Wallis chisquared $\mathrm{p}=0.75$ ) and Constant scores (Kruskall-Wallis chi-squared $\mathrm{p}=0.69$ ) when comparing the three groups (Table III).

\section{Comparison of MRI findings}

When assessing the fatty infiltration, atrophy and tear size, the C3 tears did have a statistically higher chance of having fatty infiltration (Pearson chi-squared $p=0.028$ ). The $C 3$ tears also had significant atrophy (Pearson chi-squared $p=0.032$ ), as indicated by the tangent sign (Tables IV and $V$ ).

In the $\mathrm{C} 2$ group, two of the full thickness tears were now reported as being partial thickness tears and smaller in dimension than reported on initial surgical assessment. This equates to $12 \%$ of the total number of shoulders assessed (Cl: 1.4-36.4).

The association between increasing age and atrophy Wilcoxon rank-sum $(p=0.05)$ was also noted to be significant, as well as age and fatty infiltration Wilcoxon rank-sum $(p=0.008)$.

The comparison between fatty infiltration stages and abduction strength revealed that stage $0(n=2)$ had mean strength of $9.4 \mathrm{~kg}$ $(4.8 \mathrm{~kg}-14.0 \mathrm{~kg})$; stage $1(\mathrm{n}=6)$ abduction strength mean $16.0 \mathrm{~kg}$ (range $6.6 \mathrm{~kg}-22 . \mathrm{kg}) ;$ stage $2(\mathrm{n}=4)$ mean abduction strength $10.4 \mathrm{~kg}$ (range $5.3 \mathrm{~kg}-15.3 \mathrm{~kg}$ ); stage $3(\mathrm{n}=1)$ abduction strength $3.5 \mathrm{~kg}$; and the stage $4(\mathrm{n}=4)$ abduction strength was $4.2 \mathrm{~kg}$ (range $1.4 \mathrm{~kg}-8.4 \mathrm{~kg}$ ). There was a statistically significant association between muscle atrophy and abduction strength, Spearman's $\mathrm{p}=0.009$ (Table VI). 


\section{Discussion}

The reason for progression of isolated tears of the rotator cuff in impingement syndrome is multifactorial. Understanding the natural history of rotator cuff tears is important when evaluating whether acromioplasty has any effect on rotator cuff tear progression.

The article by Melis et al. ${ }^{10}$ that looked at the natural history of fatty infiltration and atrophy in tears of the supraspinatus muscle, suggests that tears progressed to stage 2 fatty infiltration by four years and severe fatty infiltration (stage 3/4) by six years. Traumatic tears progressed faster, and fatty infiltration of at least stage 2 was present at three years. Muscle atrophy was noted in all tear types to occur at an average of 4.5 years post-symptomatic onset. We did not see this progression in atrophy and fatty infiltration in the small isolated tears of the rotator cuff in our study.

This assumption that all tears progress is now being disputed. Fucentese et al. and Maman et al. ${ }^{11,12}$ have both shown that small tears may get smaller and may even heal if they are isolated tears. The progression of isolated rotator cuff tears in the context of impingement syndrome following acromioplasty and subacromial decompression has not yet been quantified. In this study we confirmed that small tears may appear to heal on MRI, and our figure of $12 \%$ is in keeping with the literature of $8-9 \%{ }^{11,12}$ healing rates in patients without impingement syndrome.

The aetiology of rotator cuff tears in impingement syndrome can be attributed to extrinsic, intrinsic and genetic factors.

Acromial morphology as an extrinsic cause for rotator cuff tears and their progression is well described. A recent article ${ }^{13}$ looking at relationship of radiographic acromial characteristics and rotator cuff diseases showed that the presence of an acromial spur is highly associated with a rotator cuff tears in the symptomatic and asymptomatic patient. In Bigliani's ${ }^{4}$ description of acromial morphology, a type 3 acromion has a higher incidence of rotator cuff tears. However, in the Maman et al. ${ }^{12}$ review there was no statistical correlation between acromial spur and rotator cuff tears. The presence of an acromial spur or abnormal acromial morphology does not always correlate with clinical impingement symptoms. Therefore, there has been suggestion that intrinsic causes may be responsible for symptomatic impingement syndrome and rotator cuff degeneration.

The intrinsic theories of cuff degeneration and tears suggest that there is a zone of hypovascularity and relative hypoxia that may lead to apoptosis and rotator cuff damage. ${ }^{14-16}$ This abnormal cuff is now dysfunctional which results in an uncentred high riding humeral head which causes the acromial morphological changes.

Articular-sided tears are also more common than bursal-sided tears, which may suggest intrinsic pathology. Ogata and Uhthoff ${ }^{17}$ showed that cuff degeneration and tears progress with age but acromial degeneration did not. Hyvönen et $a l .^{18}$ reported that open acromioplasty did not prevent tear progression in impingement syndrome as they found that tears may appear after acromioplasty in the shoulder where no tear was present at time of surgery.

There have also been studies looking at surgical versus nonsurgical or structured exercise regimens for the treatment of impingement syndrome, which have shown that long-term outcomes are similar when comparing acromioplasty versus nonsurgical interventions. ${ }^{19-21}$

A randomised controlled study performed by Kukkonen et al. ${ }^{1}$ demonstrated that operative treatment is no better than conservative treatment in the management of supraspinatus tears in impingement syndrome. Follow-up was one year in this study. Kukkonen suggests that conservative treatment be the primary method of treatment. ${ }^{1}$
These findings may support the theories that cuff degeneration is due to intrinsic mechanisms, and surgery may not alter the natural history of rotator cuff pathology in impingement syndrome.

There has been evidence to suggest that rotator cuff pathologies and symptoms may be genetic and there is a subset of patients that have increased genetic susceptibility in developing tears and subsequent tear progression. Harvie et al. ${ }^{22}$ has shown that siblings have a 2.42 relative risk of developing full thickness rotator cuff tears and a 4.65 relative risk of the tears being symptomatic.

The variability noted in the healing response of the rotator cuff in a cross-section of patients is now being attributed to alterations in genetic expression. Genetic expression which controls cellular, vascular and extracellular matrix formation is controlled by biological and local mechanical factors at the tendon edge. It is postulated that surgical repair alters the biological environment at the tendon edge and therefore modulates gene expression. ${ }^{23}$ Repair of the rotator cuff in sheep and rabbits however, has not shown to reverse fatty infiltration, but early repair may result in partial recovery according to Kang and Gupta, ${ }^{15}$ and therefore early repair in the traumatic full thickness tears and early presenting degenerative tears is still of value. Established stage 3 and 4 fatty infiltration and atrophy; however, was not reversible with surgical repair. ${ }^{10,11,24}$ The genetic expression of protein degradation genes which results in proteolysis and muscle degeneration is up-regulated in massive rotator cuff tears. ${ }^{25}$ This may explain the association with larger rotator cuff tears and significant fatty infiltration and atrophy.

The pathophysiology of fatty degeneration is related to unloading of the muscle due to its loss of insertion into bone; this result in changes in physiological structure and function of the muscle and ultimately atrophy. ${ }^{24,26}$ This unloading of the muscle may ultimately be the reason that the larger tears progressed with respect to fatty changes and atrophy. In smaller tears there is less unloading of the muscle and therefore less propensity to atrophy and degeneration.

The rotator crescent and rotator cable theory by Burkhart et al. ${ }^{3}$ describes two distinct areas of the rotator cuff with different load characteristics. The rotator cable which is relatively thicker supports more load and shields the crescent area. Burkhart hypothesised that as people age there is progressive thinning of this relatively avascular crescent zone. This hypothesis has been recently supported by Kim et al. ${ }^{27}$ who have shown that most degenerative tears occur in a more posterior location near the junction of the infraspinatus and supraspinatus and not anteriorly as initially thought. The biomechanical relevance of this tear position is that the cable is still intact, which has been shown in biomechanical studies by Meisha et al. ${ }^{28}$ to be the primary load-bearing structure in the supraspinatus. Therefore, tear position and not only tear size are important to consider when assessing the clinical effects of rotator cuff tears. In this study it was noted at arthroscopy that all the $\mathrm{C} 1$ and $\mathrm{C} 2$ tears were within this cable, hence the good clinical parameters achieved by the study participants.

The fibrogenic and adipogenic progenitor cells in muscle that are responsible for fatty change are normally inactive in healthy muscle. The activation and differentiation of these cells has been found to be initiated by ageing, oxidative stress and muscle degeneration. This fibroproliferative response in the older patient negatively affects the rotator cuff muscle's ability to regenenerate. ${ }^{24,26}$ The age of the patient is therefore important in assessing the healing capability of a rotator cuff tear and is of relevance in this study as we had an elderly patient cohort.

In this study it was noted that isolated small full thickness tears had the best outcomes when assessing the clinical parameters of Constant and Oxford scores. The small tears also had better structural outcomes, whereas the larger tears did considerably 
worse structurally but not clinically. Norlin and Adolfsson ${ }^{25}$ concluded that small full thickness tears do well post acromioplasty at 10 to 13 years post-surgery, which correlates with our findings.

Ozaki et al. ${ }^{30}$ showed that $38 \%$ of cadavers over 60 years had cuff tears; this figure rose to $80 \%$ in cadavers over 90 years of age, where most of these tears are asymptomatic. The prevalence of asymptomatic full thickness tears in the population aged $40-60$ years is $4 \%$ and patients over 60 years is $24 \%$, according to an MRI study by Sher et al. ${ }^{31}$ From this data it can be noted that rotator cuff tears are relatively common and that not all patients with cuff tears present with a loss in function or pain, which might explain the good clinical outcomes we found in this age group of patients.

Weaknesses of this study include poor patient follow-up, and low numbers available for this study which was due to the fact that 11 patients had died, seven were too ill, eight patients refused, five had moved and 15 were not contactable. The patients were also pre-selected as having good functional capacity prior to surgery which was one of the reasons not to repair the rotator cuff. No preoperative MRI was done to evaluate progression of fatty infiltration and atrophy with current MRI findings at follow-up.

\section{Conclusions}

Currently this is the only long-term MRI study of patients with full thickness supraspinatus tears that were not repaired at the time of acromioplasty.

This small cohort of patients had good long-term clinical outcomes irrespective of tear size. It also showed that not all tears progressed to significant fatty change and atrophy in the long term. Full thickness tears may progress or heal despite surgical intervention. The process of muscle regeneration or degeneration in muscles with tears seems to be more influenced by local biological factors, genetic expression and tear location, and therefore acromioplasty in isolation does not influence rotator cuff tear healing. The recommendation that can be made from this study is that small tears within the cable do not need to be fixed and in this elderly population this would facilitate less rehabilitation and earlier mobilisation. Larger C3 tears, upon discussion with the patient, can be treated without repair and with shorter rehabilitation time if patients are willing to accept some functional loss.

\section{Ethics statement}

This study received approval by the Human Research Ethics Committee, University of Cape Town: ref number 183/2013.

\section{Declarations}

The authors declare authorship of this article and that they have followed sound scientific research practice. This research is original and does not transgress plagiarism policies.

\section{Author contributions}

$\mathrm{DC}$ was the primary author and researcher. AL was the primary surgeon in all the cases mentioned and provided the patient data base. BV reviewed the written submission. $\mathrm{RD}$ contributed in data collection and research. SR provided the original idea and assisted in writing the article.

\section{ORCID}

D Chivers (D) http://orcid.org/0000-0001-7896-9688

R Dachs (iD http://orcid.org/0000-0002-4394-6627

\section{References}

1. Kukkonen J, Joukainen A, Lehtinen J, Mattila KT, Tuominen EK, Kauko $\mathrm{T}$, et al. Treatment of non traumatic rotator cuff tears, a randomised control trial with one year clinical follow-up.
The Bone and Joint Journal 2014;96-B:75-81. http:// dx. doi: 10.1302/0301-620X.96B1.32168

2. Snyder SJ,editor. Arthroscopic classification of rotator cuff lesions and surgical decision making. In: Shoulder Arthroscopy. 2nd edition. Philadelphia Lipencott Williams \& Wilkins; 2003. pp 201-207.

3. Burkhart SS, Esch JC, Jolson RS. The rotator crescent and rotator cable : an anatomic description of the shoulder's 'suspension bridge'. Arthroscopy: The Journal of Arthroscopic and Related Surgery 1993:9(6):611-16.

4. Bigliani BU, Morrison ES, April EW. The morphology of the acromion and its relationship to rotator cuff tears. Orthop Trans 1986;10:216.

5. Goutallier D, Postel JM, Bernageau J, Lavau L, Voisin MC. Fatty muscle degeneration in cuff ruptures. Pre and postoperative evaluation by CT scan. Clin Orthop Relat Res.1994;304:78-83.

6. Fuchs B, Weishaupt D, Zanetti M, Hodler J, Gerber C. Fatty degeneration of the muscles of the rotator cuff: assessment by computed tomography versus magnetic resonance imaging. $J$ Shoulder Elbow Surg. 1999;8:599-605.

7. Zanetti M, Gerber C, Hodler J. Quantitative assessment of the muscles of the rotator cuff with magnetic resonance imaging. Invest Radiol. 1998;33:163-70.

8. Constant $\mathrm{CR}$, Murley AH. A clinical method of functional assessment of the shoulder. Clin Orthop Relat Res.1987;214:160-64.

9. Dawson J, Fitzpatrick R, Carr A. Questionnaire on the perception of patients about shoulder surgery. Journal of Bone and Joint Surgery. 1996;78:593-600.

10. Melis B, DeFranco MJ, Chuinard C, Walch G. Natural history of fatty infiltration and atrophy of the supraspinatus muscle in rotator cuff tears. Clin Orthop Relat Res. 2010;468(6):1498-1505. http:// dx. doi: 10.1007/s11999-009-1207-x

11. Fucentese SF, Von Roll AL, Pfirrmann WA, Gerber C, Jost B. Evolution of nonoperatively treated symptomatic isolated full-thickness supraspinatus tears. J Bone Joint Surg. 2012;94(9):801. http:// dx. doi: 10.2106/JBJS.I.01286.

12. Maman E, Harris C, White L, Tomlinson G, Shashank M, Boynton E. Outcome of nonoperative treatment of symptomatic rotator cuff tears monitored by magnetic resonance imaging. $J$ Bone Joint Surgery Am. 2009;91(8):1898-1906. http:// dx. doi: 10.2106/ JBJS.G.01335

13. Hamid N, Omid R, Yamaguchi K, Steger-May, Keener JD, Stobb G. Relationship of radiographic acromial characteristics and rotator cuff disease: prospective investigation of clinical, radiographic and sonographic findings. J Shoulder Elbow Surg. 2012 Oct; 21(10):1289-98. http:// dx. doi: 10.1016/j.jse.2011.09

14. Harrison AK, Flatow EL. Subacromial impingement syndrome. $J$ Am Acad Orthop Surg. 2011;19(11):701-708.

15. Kang JR, Gupta R. Mechanisms of fatty degeneration in massive rotator cuff tears. J Shoulder Elbow Surg. 2012;21:175-80. http:// dx.oi.org/10.1016/j.jse.2011.11.017

16. Lohr JF, Uhthoff HK. The microvascular pattern of the supraspinatus tendon. Clin Orthop Relat Res 1990;254:35-38.

17. Ogata S, Uhthoff HK. Acromial enthesopathy and rotator cuff tear: A radiologic and histologic post-mortem investigation of the coracoacromial arch. Clin Orthop Relat Res. 1990;254:39-48.

18. Hyvönen P, Lohi S, Jalovaara P. Open acromioplasty does not prevent the progression of an impingement syndrome to a tear. Nine-year follow-up of 96 cases. J Bone Joint Surg Br. 1998;80(5):813-16.

19. Budoff JE, Nirschl RP, Guidi EJ. Debridement of partial thickness tears of the rotator cuff without acromioplasty: long-term follow-up and review of the literature. J Bone Joint Surg Am 1998;80(5):733-48.

20. Ketola S, Lehtinen J, Rousi T, Nissinen M, Huhtala M, Konttinen YJ, Arnala I, et al. No evidence of long-term benefits of arthroscopic acromioplasty in the treatment of shoulder impingement syndrome. Upper Limb 2013;2(7):132-39. http://dx. doi: 10.1302/2046-3758.27.2000163

21. Kuhn JE. Exercise in the treatment of rotator cuff impingement: $A$ systematic review and a synthesized evidence-based rehabilitation protocol. J Shoulder Elbow Surg 2009;18(1):138-60. http:// dx. doi: $10.4085 / 1062-6050-45.5 .483$ 
22. Harvie P, Ostlere SJ, Teh J, Mcnally EG, Clipsham K Burston BJ. Genetic influences in the aetiology of tears of the rotator cuff. Sibling risk of full-thickness tear. $J$ Bone Joint Surg $\mathrm{Br}$ 2004;86:696-700. DOI: http://dx.doi. org/10.1302/0301-620X.86B5.14747

23. Chaudhury S, Carr AJ. Lessons we can learn from gene expression patterns in rotator cuff tears and tendinopathies. $J$ Shoulder Elbow Surg 2012;21:191-99. http://dx doi: 10.1016/j. jse.2011.10.022

24. Barry J, Lansdown DA, Cheung S, Feeley BT, Benjamin C. The relationship between tear severity, fatty infiltration, and muscle atrophy in the supraspinatus. J Shoulder Elbow Surg 2013;22:1825 http://dx.doi.org/10.1016/j.jse.2011.12.014

25. Schmutz S, Fuchs T, Regenfelder F, Steinmann P, Zumstein M, Fuchs B. Expression of atrophy mRNA relates to tendon tear size in supraspinatus muscle. Clin Orthop Relat Res. 2009;467(2):45764. http://dx.doi.org/10.1016/j.jse.2011.10.022

26. Laron D, Samagh SP, Liu X, Kim HT, Feeley BT. Muscle degeneration in rotator cuff tears. J Shoulder Elbow Surg 2012;21:164-74. http://dx.doi.org/10.1016/j.jse.2011.09.027

27. Kim HM, Dahiya N, Teefey SA, Middleton WD, Stobbs G, Steger M, Yamaguchi K. Location and initiation of degenerative rotator cuff tears: an analysis of three hundred and sixty shoulders. $J$ Bone Joint Surg Am. 2010 May;92(5):1088-96.http://dx.doi.org/10.2106/ JBJS.I.00686

28. Meisha MM, Derwin KA, Sibole SC, Erdemir A, McCarron JA. The biomechanical relevance of anterior rotator cuff cable tears in a cadaveric shoulder model. J Bone Joint Surg Am. 2013 Oct 16;95(20):1817-24. http://dx.doi.org/10.2106/JBJS.L.00784

29. Norlin R, Adolfsson L. Small full-thickness tears do well ten to thirteen years after arthroscopic subacromial decompression. $J$ Shoulder Elbow Surg. 1993;17(1 Suppl):12S-16S.

30. Ozaki J, Fujimoto S, Nakagawa Y, Mashura K, Tamai S. Tears of the rotator cuff associated with pathological changes in the acromion. J Bone Joint Surg 1988;70:1224-30.

31. Sher JS, Uribe JW, Posada A, Murphy BJ, Zlatkin MB. Abnormal findings on MRI of asymptomatic shoulders. J Bone Joint Surg 1995;77:10-15. 